\title{
A preliminary analysis in the preparation and obturation of oval canals
}

\author{
Manjunath Hampanna Malur ${ }^{1}$, Mallikarjun Goud ${ }^{2}$ \\ ${ }^{1}$ BDS,MDS. Assistant Professor . Department of Conservative and Endodontics. PMNM Dental College and Hospital, Bagalkot. \\ India. \\ ${ }^{2}$ BDS,MDS. Professor and Head of the Department. Department of Conservative and Endodontics. Bapuji Dental College and \\ Hospital, Davangere. India.
}

Correspondence:

Department of Conservative and Endodontics

PMNM Dental College and Hospital

BVVS Campus, Bagalkot-587101, India

Email:drmanjunathmalur@gmail.com

Malur MH, Goud M. A preliminary analysis in the preparation and obturation of oval canals. 2011;3(3):e189-92.

http://www.medicinaoral.com/odo/volumenes/v3i3/jcedv3i3p189.pdf

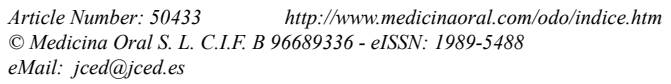

\begin{abstract}
Objective: 1) to observe the appearance of uninstrumented recesses in oval canals after instrumentation using circumferential filing.

2) To determine the quality of obturation both with cold lateral compaction and thermo plasticized gutta-percha technique in these recesses

Study design: Twenty non-carious, freshly extracted human mandibular incisors with single canals were divided into group I $(\mathrm{n}=10)$ and group II $(\mathrm{n}=10)$ according to the two different obturation methods. The sectioned roots were prepared with flexofiles (Dentsply, Maillefer) ranging from \#15 to \#40 by using circumferential filing. The obturated specimens were horizontally sectioned at $5 \mathrm{~mm}$ from the apex. Each section was observed under the stereomicroscope at $\mathrm{x} 40$ magnification. The quality of obturation in the recesses was evaluated by using 3-point scoring system; the results were subjected to statistical analysis.

Results and Conclusion: The results showed that, uninstrumented recesses might be left in many oval canals, even after circumferential filing with smaller size files. In addition, the thermoplasticized obturation technique was better in filling the recesses as compared to lateral compaction but the results were statistically insignificant.
\end{abstract}

Key Words: oval canals, circumferential filing, cold lateral condensation technique, thermoplasticized obturation technique. 


\section{Introduction}

During root canal preparation the final three dimensional preparation shape of the canal should completely encompass the initial or untreated shape of the canal. With the circular nature of the root canal instruments, this objective can be achieved only if the initial size of the canal is small or its cross sectional shape is circular. However all canals are not circular in shape, and oval canals are frequently encountered during instrumentation.

Studies reported (1), the prevalence of oval canal in the apical portion of human tooth root. An oval canal was defined in that study as one with cross sectional long: short diameter ratio of $\geq 2$. It may be difficult to instrument the entire oval canals and uninstrumented recesses may remain after preparation, involving rotation of instruments. Although these recesses may not be well cleaned, it is desirable to obturate them completely with gutta-percha and sealer because sealer may assist in microbial control. Filling these recesses may trap remaining bacteria and isolate them from sources of nutrients. However these recesses can be obturated by the current root filling techniques has not been studied.

Studies (2) have shown that, after resecting the apices of mandibular incisors the average labiolingual diameter of canal was $0.75 \mathrm{~mm}$ at $3 \mathrm{~mm}$ from the apex. They found that oval canals occupied by $40 \%$ of the investigated teeth. It seems that most canals of lower incisors were not round in shape and they were found to be long oval canals, which may be more difficult to clean, shape, and obturate. One perception is that circumferential filing could instrument these recesses with a smaller size files. However, whether that is really the case in the apical root canals remains to be confirmed because the apical portion of instruments may not be easily controlled. Also studies shown that the manner of using the instrument, rather than the type of instrument used, determines the general shape of the canal preparation. Most roots are oval in cross section and are wider buccolingually than mesiodistally. In these cases, the circumferential filing is emphasized in the buccolingual direction. The oval canal is made into a wider and larger oval. This permits easier placement of precurved instruments, gutta-percha cones, and finger spreaders.

The purpose of this study was to observe the appearance of uninstrumented recesses in oval canals after instrumentation by using circumferential filing and then to compare the quality of obturation with cold laterally condensed and thermoplasticized obturation technique in these recesses.

\section{Objectives}

To observe the appearance of uninstrumented recesses in oval canals after instrumentation using circumferential filing.

To determine the quality of obturation both with cold lateral compaction and Thermo plasticized gutta-percha technique in these recesses.

\section{Methodology}

Twenty non-carious, freshly extracted human mandibular incisors were collected from the Department of Oral and Maxillofacial Surgery, Bapuji Dental College and Hospital, Davangere. Teeth collected were extracted due to periodontal reasons. Labiolingual and mesiodistal radiographs of each tooth were made. The internal long and short diameters were measured by using these radiographs. The ratio of long: short diameter ratio found to be of $\geq 2$ at a level of $5 \mathrm{~mm}$ from the apex. None of the teeth had restorations, any regressive alterations, and roots with resorptions, fractures or open apices. Calculus and debris on the root surfaces was removed.

The crowns of all the teeth were removed at the level of cemento-enamel junction by using double-sided diamond disc. The working length was established by deducting $1 \mathrm{~mm}$ from the actual canal length, which had been determined by inserting a size 15 file into the canal until the tip of the file was just visible at the apical foramen. The coronal half of each canal was preflared using Gates Glidden drills (Dentsply Maillefer) sizes 1-3 (ISO sizes $50,70,90$ ).

All the canals were prepared with flexofiles (Dentsply, Maillefer) by one operator using circumferential filing. This technique enhances preparation when a flaring method is used by widening the orifice of the canal considerably, whereas the apical portion is kept relatively small. Teeth in both groups had similar ratios of long: short canal diameter. Each canal was irrigated with $2 \mathrm{ml}$ of fresh $2 \%$ sodium hypochlorite solution using a syringe and 27-gauge needle between each file.

The teeth were divided into two groups as; group I $(\mathrm{n}=10)$ - Lateral compaction method, and group II $(n=10)$ - Thermoplasticized obturation technique. The canals were obturated by a second operator without the knowledge of preparation technique. After drying the canal with absorbent points, zinc oxide eugenol sealer was mixed manually according to the manufacturer recommendation and introduced into the root canal with a size 15 file. A size 40 master gutta-percha cone lightly coated with sealer was placed in the canal to the full working length. Cold lateral condensation was done in each canal using size 25 accessory gutta-percha cones. The tip of each accessory gutta-percha cone was coated with sealer during obturation.

Specimens' in-group II was obturated with Ultrafil (Thermoplasticized technique) obturation using again Zinc oxide eugenol sealer. The alpha-phase gutta-percha of light bodied, Firmset supplied in disposable cannules with 22-guage needles attached were used in this study, which becomes plasticized, when placed in special heater at 70 degree centigrade. 
The filled teeth were stored in $100 \%$ humidity at 37 degree centigrade for 1 week, then after the each root were horizontally sectioned at $5 \mathrm{~mm}$ from the apex. Each section was observed under the stereomicroscope at $x 40$ magnification. Filling quality in the recesses was evaluated by using following scoring system. Score 1: No recesses, completely filled canal without the visible voids (Fig 1. a); Score 2: The recess was incompletely filled with visible voids (Fig 1. b); Score 3 (Fig 1. c): The recess was completely unfilled. Then the results were subjected to statistical analysis.
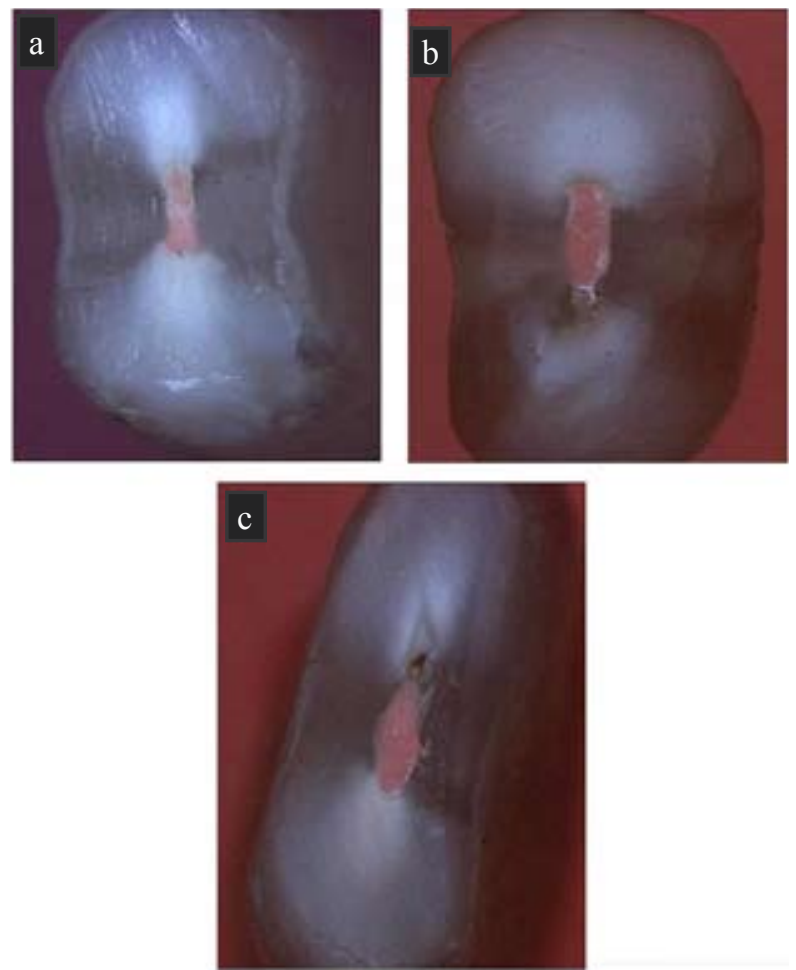

Fig. 1. a. Cross section of obturated root that completely filled without the visible voids. The Preparation of root by circumferential filing did not produce any recesses.

b. Cross section of obturated root showing presence of recess with incompletely filled visible voids

c. Cross section of obturated root. The recess was full with debris and completely unfilled.

\section{Results}

Table 1 shows the distribution of samples by groups. This table depicts that the score- 1 , that is completely filled with gutta-percha and without the recesses were seen in five canals in-group I and seven canals in-group
II. Which showed that out of 20 canals 7 canals were filled with thermoplasticized obturation technique as compared to lateral compaction which is seen in 5 canals, indicating that, the incidence of filling were more seen in thermoplasticized obturation technique as compared to lateral compaction method. Out of 20 teeth 12 teeth showed the absence of recesses and eight canals showed the presence of recesses. Which showed that even after instrumentation by using circumferential filing technique, around $40 \%$ of canals ( 8 canals) showed the presence of recesses in oval canals.

Table 2 shows mean score and standard deviation for both original scores and for percentage of filled area. Ingroup I that is, in Lateral compaction the mean score was $1.9000 \pm 0.9944$, which is more than group II that is $1.5000 \pm 0.8498$. This shows that the filling of these recesses were more seen with Group II that is Thermoplasticized obturation technique as compared to Lateral compaction method. The percentage of filled area was seen more in-group I with mean values being 97.7000 $\pm 2.4967 \%$ as compared to Group II with $98.7000 \pm$ 2.1628 .

\section{Discussion}

Wu et al (1) and Mauger et al (2) have reported the presence of $80 \%$ oval canals at $5 \mathrm{~mm}$ level from the apex in mandibular incisors as compared to the other teeth, hence in this study, sections were considered at $5 \mathrm{~mm}$ level from the apex. Studies(3) reported the use of rotary instrument in combination with single cone obturation or lateral compaction did not shown any significant differences between them in obturating the oval canals. Studies(4) also reported that instrument with greater taper (Protaper, Mtwo) were more efficient than hand files but this was in some cases at the expense of remaining dentin thickness. Hence in this study smaller size stain-

\begin{tabular}{|l|c|c|c|c|}
\hline Group & Score 1 & Score 2 & Score 3 & Total \\
\hline $\begin{array}{l}\text { LC* } \\
\text { (group I) }\end{array}$ & 5 & 1 & 4 & 10 \\
\hline $\begin{array}{l}\text { TG** } \\
\text { (group II) }\end{array}$ & 7 & 1 & 2 & 10 \\
\hline Total & 12 & 2 & 6 & 20 \\
\hline
\end{tabular}

Table 1. Distribution of samples by groups

*Lateral compaction

**Thermoplasticized gutta-percha technique

\begin{tabular}{|l|c|c|c|c|}
\hline \multirow{2}{*}{ Group } & \multicolumn{2}{|c|}{ Raw score } & \multicolumn{2}{c|}{ \% of filled area } \\
\cline { 2 - 5 } & Means & Std.Dev. & Means & Std.Dev. \\
\hline LC (group I) & 1.9000 & 0.9944 & 97.7000 & 2.4967 \\
\hline TG (group II) & 1.5000 & 0.8498 & 98.7000 & 2.1628 \\
\hline Total & 1.7000 & 0.9234 & 98.2000 & 2.3306 \\
\hline
\end{tabular}

Table 2. Mean and standard deviation of original scores and percentage of filled area. 
less steel files were used with circumferential filing method. The hypothesis behind circumferential filing is that a smaller size file can move all around the oval canal and prepare the narrow recesses in oval canals.

The long diameter of oval canals has been found to decrease apically. Therefore, the long diameter of canals at the level $3 \mathrm{~mm}$ from the apex may not be as long as that at the $5 \mathrm{~mm}$ level. This explains why uninstrumented recesses appeared less frequently at $3 \mathrm{~mm}$ level compared to the $5 \mathrm{~mm}$ level (1). So in this study sectioning were made at $5 \mathrm{~mm}$ level from the apex, in eight canals out of 20 canals uninstrumented recesses were found that is around $40 \%$ of the root canal wall, which is consistent with the previous study (5). In six canals, the recesses were completely unfilled because the recesses were narrow and long and had been filled with a large amount of debris.

On the other hand the increased flare in groups created problem during obturation using cold lateral compaction method since, the percentage of filled area were significantly lower. A number of accessory cones were required to fill the enlarged canal space. However, coronal part of the canal that had been enlarged with GG drill size 3 may have been wide enough to allow the sufficient accessory cones to be placed, resulting in a low percentage of filled area in the apical region. Studies have compared (6) the oval canals prepared to ISO size $>50$ with those prepared to size 30 or 35 . They also reported that the quality of laterally condensed gutta-percha root fillings in widely prepared canals was significantly worse. In the same study some other oval canals were prepared $>50$ and filled with warm gutta-percha, the quality of filling was found to be significantly better than the cold lateral condensation. This indicates that a warm gutta-percha technique is less influenced by widely prepared canals.

According $\mathrm{Wu}$ et al (7) superior quality of obturation was achieved consistently by the warm GP in $96 \%$ of the specimens, but in the present study no statistically significant difference was found between cold compaction and warm gutta-percha technique, although warm guttapercha technique showed the better result.

Lateral condensation remained the most widely used gutta-percha obturation techniques. However, this technique produced many irregularities in the final mass of gutta-percha. Studies (8) also reported a limited ability to fill oval canals in the various thermoplasticized techniques with lateral compaction.

Overall, the circumferential filing with smaller size files left recesses at $5 \mathrm{~mm}$ level from the apex. Importantly the efficacy of irrigation should be enhanced, perhaps by raising the temperature, concentration and volume of $\mathrm{NaOCl}$ solution. Meanwhile ultrasonic irrigation with file oscillating towards the oval recesses was indicated to promote cleaning (9).

\section{Conclusion}

1) Uninstrumented recesses may be left in many oval canals even after circumferential filing with smaller size files.

2) There is no statistically significant difference between cold lateral compaction and Thermoplasticized guttapercha in filling recesses with oval canals.

\section{References}

1. Wu MK, R'oris A, Barkis D, Wesselink PR. Prevalence and extent of long oval canals in the apical third. Oral Surg Oral Med Oral Pathol Oral Radiol Endod. 2000; 89: 739-43.

2. Mauger MJ, Schindler WG, Walker WA. An evaluation of canal morphology at different levels of root resection in mandibular incisors. J Endod. 1998; 24: 607-9.

3. Ozawa T, Taha N, Nesser HH. A comparison of techniques for obturating oval-shaped root canals. Dent Mater J. 2009; 28: 290-4.

4. Elayouti A, Chu AL, Kimionis I, Klein C, Weiger R, Löst C. Efficacy of rotary instruments with greater taper in preparing oval root canals. Int Endod J. 2008; 41:1088-92.

5. Wu MK, van der Sluis LW, Wesselink PR. The capability of two hand instrumentation techniques to remove the inner layer of dentine in oval canals. Int Endod J. 2003; 36: 218-24.

6. Kersten HW, Fransman R, Thoden van Velzen SK. Thermomechanical compaction of gutta-percha. II. A comparison with lateral condensation in curved root canals. Int Endod J. 1986; 19: 13440.

7. Wu MK, Kast'áková A, Wesselink PR. Quality of cold and warm gutta-percha filling in oval canals in mandibular premolars. Int Endod J. 2001; 34: 485-91.

8. De-Deus G, Reis C, Beznos D, de Abranches AM, Coutinho-Filho T, Paciornik S. Limited ability of three commonly used thermoplasticized gutta-percha techniques in filling oval-shaped canals. $\mathrm{J}$ Endod. 2008; 34: 1401-5.

9. Lumley PJ, Walmsley AD, Walton RE, Rippin JW. Cleaning of oval canals using ultrasonic or sonic instrumentation. J Endod. 1993; 19: 453-7. 